\title{
Prevalence of Hepatitis B Virus (HBV) Infection Among Hmong Immigrants in the San Joaquin Valley
}

\author{
Muhammad Y. Sheikh • Mouatou Mouanoutoua • \\ Matthew D. Walvick • Leepao Khang · Jasjit Singh • \\ Steven Stoltz $\cdot$ Paul K. Mills
}

Published online: 8 June 2010

(c) The Author(s) 2010. This article is published with open access at Springerlink.com

\begin{abstract}
Chronic hepatitis B infection (HBV) is the major cause of primary liver cancer worldwide and Asians are disproportionately affected. The prevalence of $\mathrm{HBV}$ among most Asian American groups has been well documented, except in Hmong immigrants in the United States. The aim of this study was to determine the prevalence of HBV among Hmong immigrants in the San Joaquin Valley of California. A convenient sample of 534 Hmong age $\geq 18$ years was recruited at various locations throughout Fresno County. Blood samples from study participants were collected and tested for hepatitis B surface antigen (HBsAg) by enzyme-immunoassay. Two hundred and eighty-nine females and 245 males of Hmong descent (mean age, 43.93) were screened. Eighty-nine (41 males and 48 females) were positive for HBsAg, which accounts for a prevalence of $16.7 \%$ (95\% C.I. 13.5-19.9). The majorities of HBsAg positive patients were $\geq 40$ years (64.2\%), married (66.7\%), born in Laos (87.3\%), and had lived in the United States $\geq 20$ years $(62.5 \%)$. Only $37.5 \%$ of the participants reported having a primary care
\end{abstract}

\footnotetext{
M. Y. Sheikh $(\bowtie) \cdot$ L. Khang

Division of Gastroenterology and Hepatology, Community Regional Medical Center, University of California San Francisco (UCSF) Fresno Medical Education Program (MEP), 2826 Fresno Street, Endoscopy Suite, 1st Floor, Fresno, CA 93701, USA e-mail: msheikh@fresno.ucsf.edu
}

\section{Y. Sheikh}

Division of Gastroenterology and Hepatology, University of California San Francisco (UCSF) Fresno MEP, Fresno, CA, USA

M. Mouanoutoua - M. D. Walvick · J. Singh · S. Stoltz · P. K. Mills

Department of Internal Medicine, UCSF Fresno,

Fresno, CA, USA physician. Our study revealed that approximately one out of every six Hmong immigrants screened was infected with HBV. Based on our findings, more than one-third of these infected patients have no primary care physician to provide further treatment, surveillance for liver cancer, or vaccination of their families. This supports the Institute of Medicine's recent recommendations to the Center for Disease Control to engage in a national Hepatitis B surveillance system.

Keywords Hepatitis B - Hmong - Hepatocellular cancer

\section{Introduction}

HBV is endemic in the Asia-Pacific region. Many studies have suggested that this is due to vertical transmission from mother to newborn coupled with low vaccination rates [1, 2]. Approximately $90 \%$ of infants and $25-50 \%$ of children aged 1-5 years will remain chronically infected with HBV after exposure [3]. Twenty-five percent of those who become chronically infected during childhood and $15 \%$ of those who become chronically infected after childhood die prematurely from cirrhosis or liver cancer $[4,5]$. In the United States, there are an estimated 1.25 million people with chronic HBV infection [6, 7]. The prevalence of chronic HBV infection in Asian Americans is between 10 and $15 \%$ compared to only $0.3 \%$ for the general United States population [8]. Chronic HBV infection is a major cause of hepatocellular carcinoma (HCC). A recent Taiwanese study reported $94.9 \%$ infection rate with $\mathrm{HBV}$ at the time of HCC diagnosis [9]. HCC is the leading cause of death among Asian Americans between the ages of 25-65 [10-12]. In the United States, chronic HBV infection results in estimated 2,000-4,000 deaths per year [3]. 
Approximately 12 million Asian Americans currently reside in the United States; of these, 5-10\% of first-generation immigrants may be chronically infected with HBV. Thus, the true prevalence of chronic HBV infection is probably in excess of 2 million. On the basis of immigration patterns in the last decade, it is estimated that every year 40,000-45,000 people from HBV-endemic countries legally immigrate to the United States. In addition, approximately 45,000 new HBV infections occur each year. The prevalence of HBsAg among Asian refugees entering the United States between 2006 and 2008 has been reported as $4.8 \%$ [13]. In 2001, the lead author of our study participated in a prospective survey of Vietnamese immigrants in Orange County, California and found that $12.9 \%$ were HBsAg positive [14].

Several studies have demonstrated the prevalence of HBV among other Asian groups in the United States, however, there are no prospective data available for the Hmong population. A retrospective study conducted in St. Paul, Minnesota found that Hmong Americans have an $18 \%$ prevalence of $\mathrm{HBV}$, with the rate of infection being highest among patients who were between 15 and 19 years of age [15]. Another retrospective study from Michigan reported that Hmong Americans had the highest prevalence rate of HBV infection among those screened [16].

In the mid 1970s after the Vietnam War, large numbers of Hmong began arriving in the United States as refugees from Laos. According to the United States Census bureau in 2000, there were approximately 186,310 Hmong in the United States. The San Joaquin Valley in California is one of the fastest growing Hmong communities with a population estimated at 65,095 [17]. There are limited data regarding the health status of the Hmong in central valley especially morbidity and mortality associated with cancer $[18,19]$. To date, there is no prospective HBV screening study in the Hmong population. Therefore, the prevalence of HBV among Hmong in San Joaquin Valley remains unknown. Such screening is essential to educate this population about the risks associated with $\mathrm{HBV}$ and optimize strategies for early detection and prevention of HCC [2022]. The objective of this HBV screening study was to determine the prevalence of HBV among Hmong population residing in Fresno County.

\section{Methods}

Sampling and Recruitment

Serological screening was provided to 534 Hmong age $\geq 18$ years between December 2006 and December 2008 . Recruiting efforts took place at many popular Hmong locations in the Fresno area. Local Hmong were made aware of the screening through several means including newspaper, frequent radio announcements, and flyers in Hmong. Educational slide presentations were delivered at Hmong church gatherings prior to all screening sessions. Two consecutive years at the International Hmong New Year Celebration in Fresno, stations for screening were established and educational material was provided. Blood samples were collected, coded, centrifuged on-site, and serum was tested for HBsAg by enzyme-immunoassays at a local laboratory.

After signing an informed consent, the study participants were given a choice of either a Hmong or English demographic and medical history questionnaire to complete. Hmong research volunteers assisted the participants in completing the questionnaire. All participants were notified of their blood test result through a confidential letter. Those who were found positive for HBsAg were invited for counseling. They were educated on the modes of transmission, complications of infection, prevention strategies and treatment options of HBV. The University of California, San Francisco-Fresno Institutional Review Board approved all study procedures.

\section{Data Analysis}

The presence of HBsAg in serum was determined by enzyme-immunoassays. Descriptive statistics were calculated and reported for demographic variables such as: age, sex, birthplace, years lived in US, marital status, vaccination, and establishment of care with a primary care provider. Ninety-five percent confidence intervals (CIs) were calculated for each variable.

\section{Results}

A total of $534 \mathrm{Hmong}$ were screened for HBV infection. Of these $45.9 \%(n=245)$ were males and $54.1 \%(n=289)$ were females. The mean age was $43.94(\mathrm{SD}=15.62)$, the range being 18-90 years. The majority of the participants $(88.1 \%, n=457)$ were born outside of the United States, mainly in Laos $(80.9 \%)$. Only $37.5 \%(n=200)$ of the participants indicated that they had a primary care physician. The duration of residence in the United States was categorized into 10-year intervals, and the majority (63.6\%) had lived in the United States for about 2029 years. These characteristics are summarized in Table 1 .

Of 534 participants tested for HBsAg, 89 (41 males and 48 females) were tested positive for HBsAg with a prevalence of $16.7 \%$ (95\% CI 13.5-19.9). Among these subjects, the mean age was 45.22 years $(\mathrm{SD}=17.35)$ with a range of $18-89$ years. Nearly $92 \%(n=79)$ were born 
Table 1 Prevalence of hepatitis B virus (HBV) infection among screened participants by selected demographic characteristics

\begin{tabular}{|c|c|c|c|}
\hline \multirow[t]{2}{*}{ Characteristics } & \multirow[t]{2}{*}{$n(\%)$} & \multicolumn{2}{|c|}{ HBsAg positive } \\
\hline & & $n(\%)$ & $(95 \% \mathrm{CI})$ \\
\hline \multicolumn{4}{|l|}{ Gender } \\
\hline Male & $245(45.9)$ & $41(16.7)$ & $(12.0-21.4)$ \\
\hline Female & $289(54.1)$ & $48(16.6)$ & $(12.3-20.9)$ \\
\hline \multicolumn{4}{|l|}{ Marital status } \\
\hline Single & $134(25.1)$ & $21(15.7)$ & $(9.5-21.9)$ \\
\hline Married & $345(64.6)$ & $56(16.2)$ & $(12.3-20.1)$ \\
\hline Previously married & $34(6.4)$ & 7 (20.6) & $(7.0-34.2)$ \\
\hline No response & $21(3.9)$ & $5(23.8)$ & $(5.6-42.0)$ \\
\hline \multicolumn{4}{|l|}{ Age group (years) } \\
\hline$<30$ & 105 (19.7) & $18(17.1)$ & $(9.9-24.3)$ \\
\hline $30-39$ & 75 (14) & $11(14.7)$ & $(6.7-22.7)$ \\
\hline $40-49$ & $125(23.4)$ & $22(17.6)$ & $(10.9-24.3)$ \\
\hline $50-59$ & $104(19.5)$ & $14(13.5)$ & $(6.9-20.1)$ \\
\hline $60-69$ & $44(8.2)$ & $11(25)$ & $(12.2-37.8)$ \\
\hline$\geq 70$ & $27(5.1)$ & $5(18.5)$ & $(3.9-33.1)$ \\
\hline No response & $54(10.1)$ & $8(14.8)$ & $(5.3-24.3)$ \\
\hline \multicolumn{4}{|l|}{ Country of birth } \\
\hline Laos & $420(78.7)$ & $69(16.4)$ & $(12.9-19.9)$ \\
\hline United States & $62(11.6)$ & $7(11.3)$ & $(3.4-19.2)$ \\
\hline Thailand & $28(5.2)$ & $7(25)$ & $(9.0-41.0)$ \\
\hline Other & $9(1.7)$ & $3(33.3)$ & $(2.5-64.1)$ \\
\hline No response & $15(2.8)$ & $3(20)$ & $(0.0-40.2)$ \\
\hline \multicolumn{4}{|l|}{ Years in United States } \\
\hline$<10$ & $10(1.9)$ & $2(20)$ & $(0.0-44.8)$ \\
\hline $10-19$ & $39(7.3)$ & $10(25.6)$ & $(11.9-39.3)$ \\
\hline $20-29$ & $119(22.3)$ & $17(14.3)$ & $(8.0-20.6)$ \\
\hline$>30$ & $19(3.6)$ & $3(15.8)$ & $(0-32.2)$ \\
\hline No response & $347(65)$ & $57(16.4)$ & $(12.5-20.3)$ \\
\hline \multicolumn{4}{|c|}{ Have primary care provider (self-report) } \\
\hline Yes & $200(37.5)$ & $33(16.5)$ & $(11.4-21.6)$ \\
\hline No & $15(2.8)$ & $4(26.7)$ & $(4.3-49.0)$ \\
\hline No response & $319(59.7)$ & $52(16.3)$ & $(12.2-20.4)$ \\
\hline \multicolumn{4}{|c|}{ Vaccinated against hepatitis B (self-report) } \\
\hline Yes & $61(11.4)$ & $10(16.4)$ & $(7.1-25.7)$ \\
\hline No/not sure & $333(62.4)$ & $53(15.9)$ & $(12.0-19.8)$ \\
\hline No response & $140(26.2)$ & $26(18.6)$ & $(12.2-25.0)$ \\
\hline Overall & 534 & 89 (16.7) & $(13.5-19.9)$ \\
\hline
\end{tabular}

Hepatitis B surface antigen ( $\mathrm{HBsAg})$ tested positive

outside the United States, of which $87.3 \%$ were born in Laos. The majority were married $(67.7 \%, n=56)$ and $53.1 \%(n=17)$ had been living in the United States for about 20-29 years. Among these infected subjects, only $37.1 \%(n=33)$ reported having a primary care physician (Table 1).

\section{Discussion}

Our study found that $16.7 \%$ of Hmong in the San Joaquin Valley might be chronically infected with HBV. We did not evaluate the mode of transmission of HBV among the study participants. However, the literature suggests that the majority of Asians contract the virus during birth or in their early childhood $[1,2]$. Our study showed that nearly $92 \%$ $(n=79)$ of HBsAg positive patients were born outside the United States. It is most likely that this Hmong population was already infected at the time of immigration to the United States. Our study found that nearly $75 \%(n=63)$ of those who tested positive for HBV infection were married or previously married. Engaging in high risk behavior, such as having multiple sex partners, tattooing, and injecting drugs are not common practices in this community. A similar observation was made among Hmong in Thailand in an earlier study [23]. The majority of the participants were unaware of any known liver disease. These findings are compatible with previously published data in Asian populations [24-28].

Rein et al. [13] published a recent study reporting the prevalence of HBsAg among refugees entering the United States during 2006-2008. They report a prevalence of 6.5\% in Eastern Asians and $10.5 \%$ in Southeast Asians. The prevalence in those from Vietnam and Laos were 3.2 and $2.3 \%$, respectively. However, this study was limited due to lack of information about the age and sex of the refugees. In comparison to CDC data from 1991 [29], the prevalence in Hmong refugees decreased from 15.5 to $2.3 \%$ in 2008. This 1991 prevalence for Laos was reported for the Hmong and for other Laotians without a single population-wide estimate. The decline in prevalence may be attributed to many factors, such as increased vaccination. The prevalence of $15.5 \%$ reported in 1991 is more consistent with the prevalence reported in our study because the majority (53.1\%) of the Hmong we screened had lived in the United States for 20-29 years.

There are several limitations to our study. First, the free HBV screening sites were all located in Fresno County. Therefore, our findings may not be generalized to the Hmong population in other parts of the United States, or even to the entire Hmong population in the Central Valley due to our sampling frame. Second, the reluctance of this population to participate in screening may have affected the true prevalence. Many Hmong were afraid of getting their blood drawn and were apprehensive of the results. They were also worried about their family members knowing their health status. In the Hmong and other Asian American communities, hepatitis B may be stigmatized with having sexual partners, which can lead to ostracism. These observations are consistent with findings from other Asian American screening studies [24-28]. Therefore, the 
prevalence reported in this study may be an underestimate of the true prevalence. Nearly $62.4 \%$ of the 534 screened Hmong indicated that they were not vaccinated or were unsure of their vaccination status. The majority of these patients had no primary care physician to provide further treatment, screening for liver cancer, or offer vaccination and preventive measures to curtail the transmission of HBV to their families.

The viral hepatitis surveillance system in the United States has been highly fragmented and poorly developed. There is a paucity of knowledge and awareness about chronic viral hepatitis on the part of health care and social service providers, at risk populations, members of the public, and policy makers. There is insufficient understanding about the extent and seriousness of this public health problem and inadequate public resources have been allocated to prevention, control, and surveillance programs. Due to inaccurate estimates of the burden of disease in the United States, policy-makers and the state governments could not allocate sufficient resources to viral hepatitis prevention and control programs. Between 2007 and 2008, the California Department of Health provided vaccination against hepatitis B to nearly 30,000 individuals. However, Asians Americans comprised only $7 \%$ of the vaccinated population. STD clinics made up $63 \%$ of the setting in which vaccination occurred, with community medical centers only accounting for 7\% [30].

The Centers for Disease Control and Prevention has been recently recommended by the Institute of Medicine to conduct a comprehensive evaluation of the national viral hepatitis public health surveillance system. As per these recommendations [31] there is a need to develop specific cooperative viral hepatitis agreements with all state and county health departments to support core surveillance for viral hepatitis. This cooperative effort would support and conduct targeted active surveillance, including serologic testing, to monitor incidence and prevalence of viral hepatitis in populations not fully captured by core surveillance. The collaboration would allow key stakeholders to develop innovative and effective educational outreach programs to at risk individuals while increasing awareness in the general population.

Hepatitis B infection and its complications such as cirrhosis and HCC are largely preventable. We hope that adherence to the Institute of Medicine's recommendations will provide an opportunity to decrease the impact of this disease in Asian Americans as well as the entire global community.

Acknowledgments We would like to thank several volunteers who served as interpreters and phlebotomists for this study and helped the investigators to make this difficult screening project a success.
Open Access This article is distributed under the terms of the Creative Commons Attribution Noncommercial License which permits any noncommercial use, distribution, and reproduction in any medium, provided the original author(s) and source are credited.

\section{References}

1. Grytdal, S. P., Liao, Y., Chen, R., Garvin, C. C., Grigg-Saito, D., Kagawa-Singer, M., et al. (2009). Hepatitis B testing and vaccination among Vietnamese- and Cambodian-Americans. Journal of Community Health, 34, 173-180.

2. Shiraki, K. (2000). Perinatal transmission of hepatitis B virus and its prevention. Journal of Gastroenterology and Hepatology, $15(5$ Suppl), E11-E15.

3. Kim, W. R. (2009). Epidemiology of hepatitis B in the United States. Hepatology, 49(5 Suppl), S28-S34.

4. Chu, C. M. (2000). Natural history of chronic hepatitis B virus infection in adults with emphasis on the occurrence of cirrhosis and hepatocellular carcinoma. Journal of Gastroenterology and Hepatology, 15(5 Suppl), E25-E30.

5. Carey, W. D. (2009). The prevalence and natural history of hepatitis B in the 21st century. Cleveland Clinic Journal of Medicine, 76(Suppl 3), S2-S5.

6. McMahon, B. J. (2005). Epidemiology and natural history of hepatitis B. Seminars in Liver Disease, 25(Suppl 1), 3-8.

7. Wright, T. L. (2006). Introduction to chronic hepatitis B infection. American Journal of Gastroenterology, 101(Suppl 1), S1S6.

8. Centers for Disease Control and Prevention (CDC). (2006). Screening for chronic hepatitis B among Asian/Pacific Islander populations-New York City, 2005. MMWR Morbid Mortal Weekly Report, 55(18), 505-509.

9. Chang, M. H., You, S. L., Chen, C. J., Liu, C. J., Lee, C. M., Lin, S. M., et al. (2009). Decreased incidence of hepatocellular carcinoma in hepatitis B vaccinees: A 20-year follow-up study. Journal of the National Cancer Institute, 101, 1348-1355.

10. Do, S. (2001). The natural history of hepatitis B in Asian Americans. Asian American and Pacific Islander Journal of Health, 9(2), 141-153.

11. Lin, S. Y., Chang, E. T., \& So, S. K. (2007). Why we should routinely screen Asian American adults for hepatitis B: A crosssectional study of Asians in California. Hepatology, 46(4), 10341040.

12. Tong, M. J., \& Hwang, S. J. (1994). Hepatitis B virus infection in Asian Americans. Gastroenterology Clinics of North America, 23(3), 523-536.

13. Rein, D. B., Lesesne, S. B., O’Fallon, A., \& Weinbaum, C. M. (2010). Prevalence of hepatitis B surface antigen among refugees entering the United States between 2006 and 2008. Hepatology, 51, 431-434.

14. Bui, L. L., Cao, S., Sheikh, M. Y., Nguyen, T. D., Tran, J. D., Nguyen, B., et al. (2001). Prevalence of hepatitis B and C in the Vietnamese immigrants in Southern California. Vietnamese Pharmaceutical Journal, 1, 55-57.

15. Gjerdingen, D. K., \& Lor, V. (1997). Hepatitis B status of Hmong patients. The Journal of the American Board of Family Practicel American Board of Family Practice, 10(5), 322-328.

16. Lee, J., Lok, A. S., \& Chen, J. (2010). Hepatitis B prevalence among Asian Americans in Michigan: An assessment to guide future education and intervention strategies. Journal of Community Health. doi:10.1007/s10900-010-9237-6. 
17. Hmong 2000 Census Publication: Data and Analysis. (2004). Hmong Cultural Center and Hmong National Development. http://hmongstudies.com/2000HmongCensusPublication.pdf.

18. Mills, P. K., \& Yang, R. (1997). Cancer incidence in the Hmong of Central California, United States, 1987-94. Cancer Causes and Control, 8(5), 705-712.

19. Mills, P. K., Yang, R. C., \& Riordan, D. (2005). Cancer incidence in the Hmong in California, 1988-2000. Cancer, 104(12 Suppl), 2969-2974.

20. Wun, Y. T., \& Dickinson, J. A. (2003). Alpha-fetoprotein and/or liver ultrasonography for liver cancer screening in patients with chronic hepatitis B. Cochrane Database of Systematic Reviews (2):CD002799. doi:10.1002/14651858.CD002799.

21. Amarapurkar, D., Han, K. H., Chan, H. L., \& Ueno, Y. (2009). Asia-Pacific working party on prevention of hepatocellular carcinoma. Application of surveillance programs for hepatocellular carcinoma in the Asia-Pacific Region. Journal of Gastroenterology and Hepatology, 24(6), 955-961.

22. Lavanchy, D. (2004). Hepatitis B virus epidemiology, disease burden, treatment, and current and emerging prevention and control measures. Journal of Viral Hepatitis, 11(2), 97-107.

23. Louisirirotchanakul, S., Myint, K. S., Srimee, B., Kanoksinsombat, C., Khamboonruang, C., Kunstadter, P., et al. (2002). The prevalence of viral hepatitis among the Hmong people of northern Thailand. Southeast Asian Journal of Tropical Medicine and Public Health, 33(4), 837-844.

24. Taylor, V. M., Tu, S. P., Woodall, E., Acorda, E., Chen, H., Choe, J., et al. (2006). Hepatitis B knowledge and practices among
Chinese immigrants to the United States. Asian Pacific Journal of Cancer Prevention, 7(2), 313-317.

25. Tran, T. T. (2009). Understanding cultural barriers in hepatitis B virus infection. Cleveland Clinic Journal of Medicine, 76(Suppl 3), S10-S13.

26. Taylor, V. M., Seng, P., Acorda, E., Sawn, L., \& Li, L. (2009). Hepatitis B knowledge and practices among Cambodian immigrants. Journal of Cancer Education, 24(2), 100-104.

27. Butler, L. M., Mills, P. K., Yang, R. C., \& Chen, M. S, Jr. (2005). Hepatitis B knowledge and vaccination levels in California Hmong youth: Implications for liver cancer prevention strategies. Asian Pacific Journal of Cancer Prevention, 6(3), 401-403.

28. Wu, C. A., Lin, S. Y., So, S. K., \& Chang, E. T. (2007). Hepatitis $\mathrm{B}$ and liver cancer knowledge and preventive practices among Asian Americans in the San Francisco Bay Area, California. Asian Pacific Journal of Cancer Prevention, 8(1), 127-134.

29. Centers for Disease Control and Prevention (CDC). (1991). Screening for hepatitis B virus infection among refugees arriving in the United States, 1979-1991. MMWR. Morbidity and Mortality Weekly Report, 40, 784-786.

30. Centers for Disease Control, Prevention (CDC). (2010). The adult hepatitis vaccine project-California, 2007-2008. MMWR. Morbidity and Mortality Weekly Report, 59(17), 513-516.

31. Institute of Medicine. (2010). Hepatitis and liver cancer. A national strategy for prevention and control of hepatitis $B$ and $\mathrm{C}$. Brief Report, pp 1-4. 